\title{
Hyperglycaemia is one correlate of deterioration in vibration sense during the 5 years after diagnosis of Type 2 (non-insulin-dependent) diabetes
}

\author{
R.M.Hillson, T.D. R. Hockaday and D. J. Newton \\ Sheikh Rashid Diabetes Unit, Radcliffe Infirmary, Oxford, UK
}

\begin{abstract}
Summary. Seventy-one Type 2 (non-insulin-dependent) diabetic patients showed only a slight deterioration in mean vibration sensory threshold (measured biothesiometrically) on the feet during the 5 years from diagnosis. However, multiple linear regression analysis of the wide range of individual changes in this threshold showed as significant independent associated factors the initial sensory threshold $(p<0.001)$, age, gender, and both the mean fasting blood glucose and failure to become thinner under treatment ( $p<0.05$ for all). The relationship with fasting glucose was stronger if the pre-treatment value was included in calculation of the mean $(p<0.001)$. Mean fasting blood glucose under treatment accounted for
\end{abstract}

only a small fraction of the total variance of the deterioration of the vibration sensory threshold, but represented onetwelfth of that attributable to identified factors, and one-third of the variance ascribable to factors subject to therapy. Interim values revealed the persistent effect of hyperglycaemia over the 5 years. An increase of $1 \mathrm{mmol} / \mathrm{l}$ in mean fasting blood glucose has an equivalent effect on the sensory threshold to an extra 5 years of age.

Key words: Type 2 diabetes, mean fasting blood glucose, vibration sensory threshold, biothesiometer, age, gender, obesity.
Impaired pedal sensitivity to vibration lies between those types of diabetic tissue damage that are of immediate clinical importance and those that are imperceptible to the patient. Vibration sensitivity can be determined quantitatively with the biothesiometer [1, 2]; it deteriorates with increasing age in both diabetic and non-diabetic subjects [3], and more so in women than men [4]. Clinical reports of reduced neuropathy after lessened glycaemia lack the rigor to establish a direct association between them [1,5-7]. Reducing the hyperglycaemia of the newly diagnosed diabetic patient is accompanied by either improved biothesiometer readings [8] or quickening towards normal motor nerve conduction [9]. A recent study did not find improved conduction in sensory nerves after glycaemic improvement [10], while the improved velocity in motor nerves might have been due to other factors which were not analysed.

The sensory threshold to vibration at the ankles and toes, as measured with a biothesiometer, is reported here in 71 patients with Type 2 diabetes [11] during their first 5 years after diagnosis, and the factors associated with its deterioration are analysed.

\section{Methods}

From 1973-1975, 100 newly diagnosed Type 2 diabetic patients agreed to join a prospective study in which they were specifically examined clinically and metabolically both initially and 1,3 and 5 years later. Results reported here are those from the 71 subjects who completed all four reviews; we have excluded six who died, nine prescribed insulin within the 5 years, and 14 on whom data were incomplete. Mean age was $53.1 \pm 8.3$ years; $44 \%$.were male and $41 \%$ were treated by diet alone.

Patients were asked to join this study only if aged less than 66 years and judged clinically not to require insulin within the next week. All had a $\mathrm{K}_{\mathrm{G}}$ index [12] less than 1.0 in a $20 \mathrm{~g} / \mathrm{m}^{2}$ body surface IV glucose tolerance test, except two with a $\mathrm{K}_{\mathrm{G}}$ of less than 1.2 , but whose random blood glucose was greater than $8.5 \mathrm{mmol} / 1$ when first seen.

The periodic reviews followed an overnight fast. The 'fasting blood glucose' is the mean of samples drawn approximately 12 and 2 min before the start of glucose injection. The mean fasting blood glucose for 5 years describes the mean of the initial and 1,3 and 5 years values. Mean values 'under treatment' exclude the initial value. The patients were randomised at entry between two different sets of dietary advice, as previously described [11].

Plasma glucose was measured on an auto-analyser by the glucose oxidase (gum guiac) method of Technicon Instruments (Tarrytown, USA), and numerous metabolites were measured as previously de- 
Table 1. Mean fasting glucose values initially and during treatment, and initial vibration sensory threshold and body mass index values with alterations during treatment in 71 Type 2 diabetic patients

\begin{tabular}{|c|c|c|c|c|}
\hline & \multirow[t]{2}{*}{ At diagnosis } & \multicolumn{3}{|c|}{ Later values (fasting blood glucose) or change from initial value } \\
\hline & & 1 year & 3 years & 5 years \\
\hline $\begin{array}{l}\text { Vibration sensory threshold } \\
\text { (arbitrary units) }\end{array}$ & $29.2 \pm 10.6$ & $-0.72 \pm 8.74$ & $-0.17 \pm 6.98$ & $+0.40 \pm 7.02$ \\
\hline $\begin{array}{l}\text { Fasting blood glucose } \\
(\mathrm{mmol} / \mathrm{l})\end{array}$ & $11.3 \pm 3.7$ & $7.8 \pm 2.4$ & $7.9 \pm 2.3$ & $8.0 \pm 2.2$ \\
\hline
\end{tabular}

Results are expressed as mean \pm SD. Mean body mass index calculated from the highest remembered weights was $31.2 \pm 5.3 \mathrm{~kg} / \mathrm{m}^{2}$

Table 2. Multiple linear regression analysis of change in vibration sensory threshold during the first 5 years after diagnosis of diabetes, with mean fasting blood glucose under treatment analysed as a factor independent of pre-treatment fasting blood glucose

\begin{tabular}{|c|c|c|c|c|}
\hline & $\begin{array}{l}\text { Zero } \\
\text { order } \\
\text { corre- } \\
\text { lation, } \\
r\end{array}$ & $\begin{array}{l}\text { b Coeffi- } \\
\text { cient } \\
\pm \text { SEM }\end{array}$ & $p$ & $\begin{array}{l}\% \text { Total } \\
\text { variance } \\
\text { attributable } \\
\text { to factor }\end{array}$ \\
\hline $\begin{array}{l}\text { Initial vibration } \\
\text { sensory thresh- } \\
\text { old }\end{array}$ & -0.41 & $-0.39 \pm 0.09$ & $<0.001$ & 16 \\
\hline Age (years) & 0.06 & $0.22 \pm 0.11$ & $<0.05$ & 5 \\
\hline $\begin{array}{l}\operatorname{Sex}(M=1, \\
F=2)\end{array}$ & 0.05 & $-4.33 \pm 1.87$ & $<0.05$ & 3 \\
\hline $\begin{array}{l}\text { Mean treated } \\
\text { fasting blood } \\
\text { glucose }\end{array}$ & 0.22 & $1.03 \pm 0.48$ & $<0.05$ & 3 \\
\hline $\begin{array}{l}\text { Increase in } \\
\text { body mass } \\
\text { index } \\
\text { (0-5 years) }\end{array}$ & 0.13 & $9.68 \pm 4.44$ & $<0.05$ & 4 \\
\hline $\begin{array}{l}\text { Pre-treatment } \\
\text { fasting blood } \\
\text { glucose }\end{array}$ & 0.23 & $0.49 \pm 0.26$ & NS & 9 \\
\hline
\end{tabular}

Standard error included for the b coefficient (slope constant) NS $=$ Not significant

scribed [13, 14]. Plasma insulin [15] and growth hormone [16] were measured by radioimmunoassay.

The vibration sensory threshold (VST) was measured with the biothesiometer (Bio-Medical Instruments, Newbury, Ohio, USA) and expressed as the mean of three values for the distal plantar surface of the distal phalanx of each hallux and for each external malleolus. The biothesiometer reading ranges from 0 to 50 on a linear scale and is proportional to the square root of the amplitude of a stimulus of constant frequency: low values indicate a weak stimulus.

The body mass index [17] was calculated as $\frac{\text { weight }(\mathrm{kg})}{\text { height }^{2}\left(\mathrm{~m}^{2}\right)}$.

Results were analysed using in ICL 2980 computer (International Computers, London, UK) with the Statistical Package for the Social Sciences [18] for means $\pm S D$, for correlation coefficients and for multiple linear regression analysis. The significance of factors in this last analysis was judged from Snedecor's tables for ' $F$ ', the variance ratio [19].

\section{Results}

Some features of the patients at diagnosis (Table 1) are typical of Type 2 diabetes, and show that the initial VST varied widely. Fasting blood glucose and body mass index decreased under treatment, with the 1-year values the lowest (Table 1). VST tended to deteriorate continuously from year 1 to 5 .

Although the deterioration in VST over the 5 years ( $\triangle$ VST) was small, its standard deviation was relatively large, allowing multi-variate analysis to test whether those factors with significant 'zero order' correlations with $\Delta$ VST still correlated once interactions between factors had been allowed for. The 5-year VST correlated strongly with the initial VST $(r=0.77, p<0.001)$ and initial VST was the strongest numerical associate of $\Delta$ VST on linear regression multi-variate analysis (Table 2).

Four other factors were significantly and independently related to deterioration in VST, all with less than $5 \%$ probability of being due to chance elements in selection or measurement. The two larger zero order correlations were with mean fasting blood glucose and increase in body mass index under treatment, while greater age and male gender were also positively correlated. The different weightings that may be given to the link with mean fasting blood glucose under treatment are illustrated in Figure 1, where the factors above-listed are first shown along with the residual variation $(60 \%$ of the total variance) (Fig. 1 a), then as a percentage of the variance contributed to the regression equation by specified factors (Fig. 1 b), and finally as a percentage of factors that might be thought amenable to therapeutic manipulation (e.g. glucose or growth hormone concentrations, or body mass index, but excluding such as age or gender) (Fig. $1 \mathrm{c}$ ). Mean treated fasting blood glucose contributes progressively $3 \%, 8 \%$ and $31 \%$ of the respective total variances.

These results can be compared with analyses based on VST measurements just 1 or 3 years after diagnosis. The coefficient of the relationship between $\triangle$ VST and mean fasting blood glucose under treatment shows a linear increase with time between 1 and 5 years (Fig.2), 


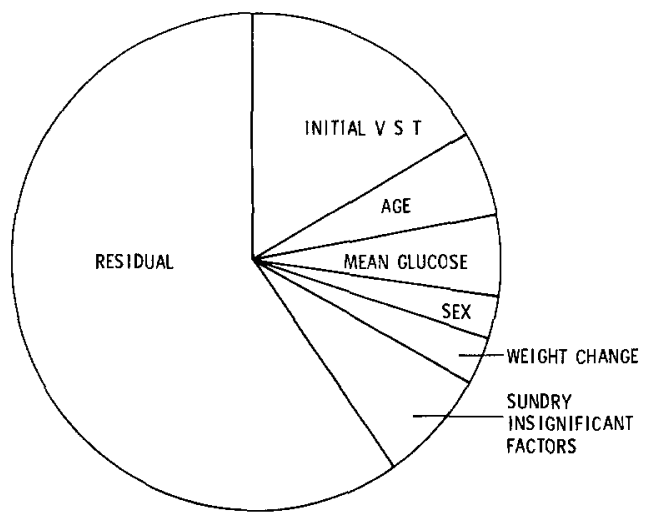

Fig. 1. Pie-diagrams of the contributions of various factors to the variance of the change in vibration sensory threshold (VST) during the first 5 years from diagnosis in 71 Type 2 diabetic patients. (a) Upper: Total variance, including residual; (b) lower left: Variance due to attributable factors, i. e. total minus residual factors; (c) lower right: Variance due to manipulatable factors, i.e. attributable minus inevitable (e.g. initial VST, gender, age) factors
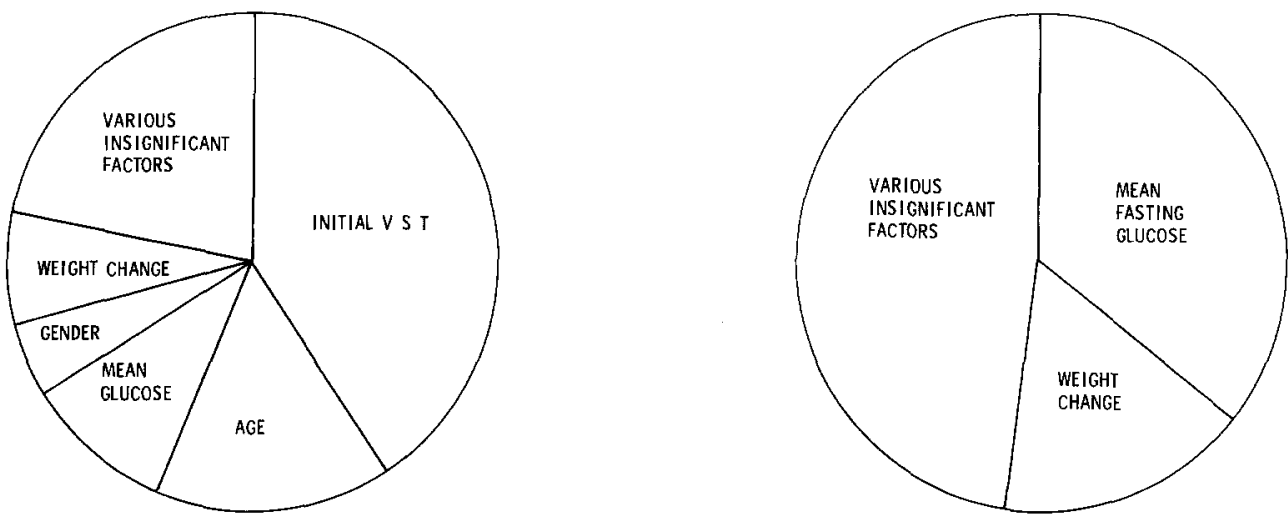

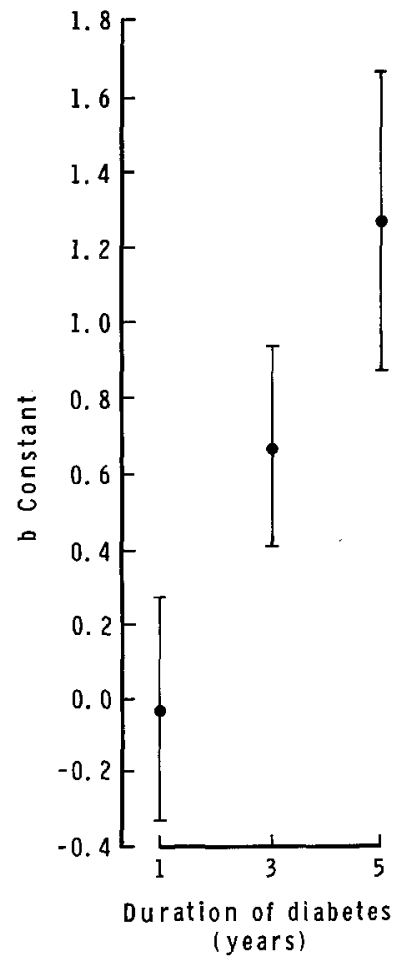

Fig. 2. From the multiple linear regression analyses of the deterioration in vibration sensory threshold (VST) 1, 3 and 5 years after diagnosis of Type 2 non-insulin-treated diabetes, the $b$ constant $\pm S E$ (for the slope of $\triangle$ VST against mean fasting blood glucose under treatment, without entry of pre-treatment fasting blood gluose) (y) is plotted against duration of recognised diabetes $(\mathrm{x}) . p<0.05$ for comparison 1 versus 5 years indicating that the risk of deterioration of VST for a given degree of hyperglycaemia is notably constant throughout the four years (even if mean fasting blood glucose is not a significant correlate of VST after just 1 year).

Other than glucose, no metabolite measured in venous blood was an independent correlate of $\triangle \mathrm{VST}$, nor were the $\mathrm{K}_{\mathrm{G}}$ index or fasting insulin or growth hormone concentrations. Treatment with sulphonylureas in addition to diet was not a numerical determinant of $\Delta$ VST (apart, that is, from possible action through altered glycaemia). Neither did the dietary randomisation, nor the blood pressure nor prescription of hypotensive agents correlate with $\triangle$ VST. The histories of smoking and of alcohol intake obtained on entry to the study were also not predictive factors.

\section{Discussion}

This study produced the conclusion expected on "classical' grounds, namely that lower glucose levels are associated in diabetic patients with less deterioration in the appreciation of vibration over the feet. Although not an important property in itself, loss of vibration sense correlates with loss of position sense and, in general, development of peripheral sensory neuropathy is linked with the appearance of diabetic retinopathy [20]. It may be emphasised that the study ran from the time of diagnosis (though hyperglycaemia doubtless preceded this), 
that the same group of patients was analysed throughout, and that the link between glucose levels and tissue damage was demonstrable after as short a time as 3 years.

It is important to know whether the hyperglycaemic promotion of tissue damage depends on any increase above a glycaemic threshold or increases proportionately over the whole range of mean fasting glucose values (here $5-12 \mathrm{mmol} / \mathrm{l}$ ). As far as our number of patients allows the distinction, the relationship appeared a linear, and not curvilinear, correlation over the whole range. Contrariwise, a threshold effect has been suggested for the effect of hyperglycaemia on development of retinopathy [21].

It will not surprise those working in diabetic clinics that the fasting glucose level was not the only factor numerically determining $\triangle$ VST. Age and gender have both previously been suspected to influence development of diabetic tissue damage. Weight reduction by obese diabetics is widely recommended but one cannot be certain that its beneficial influence here (independent of associated reduction in fasting blood glucose) is not based on technical factors involved in the biothesiometer measurements. However, this is made less likely by analysis of factors associated with the pre-treatment VST values, for the body mass index calculated from the highest remembered weight is more closely linked with the VST at diagnosis than the coincident body mass index.

Such analysis of variance helps to place the influence of glycaemia in perspective. Thus, the mean fasting blood glucose values account for less than $10 \%$ of the total variance and, over the 5 years, are a weaker influence than the initial VST. However, as emphasised in Figure 1, fasting blood glucose values loom large on considering their contribution to the variance in $\triangle$ VST attributable to factors that might, even theoretically, be open to therapeutic manipulation.

The size of the residual (non-accountable) variance will depend upon both the technical and biological accuracy of the measurements of the factors involved; it may be questioned how accurately a mean fasting blood glucose derived from four measurements over 5 years reflects the glycaemic levels prevailing throughout the study. In a sense it makes identification of blood glucose as a significantly related factor all the more impressive; but the inaccuracy may not be great, as single fasting values correlate strongly with more sophisticated measures of glycaemic control in Type 2 diabetic patients [22, 23].

Multi-variate analysis states the gradient of risk for each factor. Thus, one unit of deterioration of VST may be linked, for example, to either an increase in mean fasting blood glucose of (approximately) $0.75 \mathrm{mmol} / 1$, or an extra 4 years of age. The benefit of female gender corresponds to just a quarter of a VST unit.

In Figure 2 the long recognised importance of duration of diabetes [7] in evolution of diabetic tissue damage is confirmed.
The primacy of glucose among circulating metabolites as a quantitative index of liability to development of this form of tissue damage lightens the doubts previously expressed as to whether glucose is the best haemic factor by which to express 'diabetic control' [24].

Finally, three points should be emphasized. First, what applies to one type of diabetic tissue damage may not apply to another, just as what applies to Type 2 diabetics may not apply to Type 1 patients. Secondly, the large residual variance of the deterioration in VST illustrated the great differences between individuals, as well as providing a stimulus to categorise other responsible factors. And, lastly, these findings increase the weight of evidence pointing to the need to restore blood glucose in diabetics as near to normal concentrations as is possible and safe.

Acknowledgements. We thank greatly Mrs. C. Whitwell and Mrs. B. Pim for nursing care and clinical measurements; Dr. R. Wilkinson and the Department of Clinical Biochemistry, Oxford Hospitals, for the glucose measurements; Mr. D. Howarth and other members of the Dieticians" Department of the Oxford Hospitals for the design of the dietary regimes and instructing patients in them; Mrs. H.Dhar and Mrs. S. Humphreys for hormone and metabolite assays; Mrs. B. Smith and Dr. R. R. Holman for statistical analysis; and Mrs. D. Renton for preparing the manuscript. We have been generously supported in this work by the British Diabetic Association, the International Sugar Corporation Research Fund, and the Oxford Diabetes Trust.

\section{References}

1. Barach JH (1947) Tests for quantitative vibratory sensation in diabetes, pernicious anaemia and tabes dorsalis: diagnostic and prognostic values. Arch Int Med 79: 602-613

2. Mirsky IA, Futterman P, Broh-Kahn RH (1953) The quantitative measurement of vibratory perception in subjects with and without diabetes mellitus. J Lab Clin Med 41: 221-235

3. Steiness I (1963) Diabetic neuropathy - vibration sense and abnormal reflexes in diabetics. Acta Med Scand 173 (Suppl 394) 1-91

4. Gregersen G (1968) Vibratory perception threshold and motor conduction velocity in diabetics and non-diabetics. Acta Med Scand 183: 61-65

5. Rundles RW (1945) Diabetic neuropathy; general review with report of 125 cases. Medicine (Balt) 24: 111-160

6. Bonkalo A (1950) Relation between neuritis and the clinical background. Arch Int Med 85: 944-954

7. Pirart J (1978) Diabète et complications dégénératives. Présentation d'une étude prospective portant sur 4400 cas observés entre 1947 et 1973 (Troisième et dernière partie). Diabete Métab 3: 245-256

8. Gregersen G (1967) Diabetic neuropathy: influence of age, sex, metabolic control, and duration of diabetes in motor conduction velocity. Neuropathy 17:972-980

9. Gregersen G (1968) Variations in motor conduction velocity produced by acute changes in the metabolic state of diabetic patients. Diabetologia 4: 273-277

10. Graf RJ, Halter JB, Pfeifer MA, Halar E, Brozovitch F, Porte D (1981) Glycaemic control and nerve conduction abnormalities in non-insulin-dependent diabetic subjects. Ann Int Med 94: 307-311

11. Hockaday TDR, Hockaday JM, Mann JI, Turner RC (1978) Prospective comparison of modified fat and low carbohydrate dietary advice in the treatment of diabetes. Br $\mathbf{J}$ Nutr 39: 357-362 
12. Conard V, Francksom JRM, Basternie PA, Kestens J, Kovacs L (1953) Etude critique du triangle d'hyperglycémie d'un coefficient d'assimilation glucidique. Arch Int Pharmacodyn Ther 93: 277-292

13. Searcy RL, Bergquist LM (1960) A new color reaction for the quantitation of serum cholesterol. Clin Chim Acta 5: 192-199

14. Alberti KGMM, Record CO, Williamson DH, Wright R (1972) Metabolic changes in active chronic hepatitis. Clin Sci 42: 591-605

15. Albano JDM, Ekins RP, Maritz G, Turner RC (1972) A sensitive precise radio-immunoassay of serum insulin relying on charcoal separation of bound and free hormone moieties. Acta Endocrinol 70: 487-509

16. Boden G, Soeldner JS (1967) A sensitive double antibody radioimmunoassay for human growth hormone (HGH): levels of HGH following rapid tolbutamide infusion. Diabetologia 3: 143-421

17. Keys A, Aravanis C, Blackburn $H$, van Buchem FSP, Buzina R, Djordjevic BS, Fidanza F, Karvonen MJ, Menotti A, Puddu V, Taylor L (1972) Coronary heart disease: overweight and obesity as risk factors. Ann Intern Med 77: 15-27

18. Nie NH, Hadonaihull C (1975) Statistical package for the social sciences. McGraw-Hill, New York

19. Snedecor GW (1956) Statistical methods, 5th edn. Ames, Iowa State College Press

20. Root HF, Pote WH Jr, Frehner H (1954) Triopathy of diabetes: se- quence of neuropathy, retinopathy and nephropathy in 155 patients. Arch Intern Med 94: 931-941

21. Derf A, Ballintine EJ, Bennett PH, Millner MN (1976) Retinopathy in Pima Indians: relationship to glucose level, duration of diabetes, age at diagnosis of diabetes and age at examination in a population with a high prevalence of diabetes mellitus. Diabetes 25: $554-560$

22. Paisey RB, Bradshaw P, Hartog M (1980) Home blood glucose concentrations in maturity-onset diabetes. Br Med J 1: 596-598

23. Holman RR, Turner RC (1980) The basal plasma glucose: a simple relevant index of maturity-onset diabetes. Clin Endocrinol 14: $279-286$

24. Alberti KGMM, Dornhorst A, Rowe AS (1975) Metabolic rhythms in normal and diabetic man: studies in insulin-treated diabetes. In: Shafrir E (ed) Contemporary topics in the study of diabetes and metabolic endocrinilogy. Academic Press, London, pp 45-54

Received: 29 September 1982

and in revised form: 26 September 1983

Dr. T.D. R. Hockaday

Radcliffe Infirmary

Oxford OX2 6HE, UK 